\title{
Surface Grinding Characteristics of Ti-6Al-4V
}

\author{
Alloy \\ *Aritras Roy ${ }^{1}$, Kanchan Maji ${ }^{2}$, Sudin Kumar Kundu ${ }^{3}$ \\ 1,2,3 Department of Mechanical Enineering, Birbhum Institute of Engineering E Technoloy, \\ Suri, Birbhum, Pin-731101 \\ Email: ${ }^{1}$ aritrasroy73@mail.com, ${ }^{2} k a n c h a n . m j 50 @ g m a i l . c o m,{ }^{3}$ skkundume@gmail.com
}

\begin{abstract}
Force measurement and the surface texture characteristics on Ti-6Al-4V have been studied experimentally at up grinding condition. Grinding of Ti- $6 \mathrm{Al}-4 \mathrm{~V}$ is tough; because it creates wheel loading, lumped mass creating, wheel sticking at the time of operation, but grinding is essential because it is one of the machining processes which offer better mass production as well as it is techno economical too. Titanium alloy bar is grinded in dry condition with silicon carbide (coarse, fine) grinding wheel with the feed variation of 0.1 to $10 \mu \mathrm{m}$ and depth of cut variation of 1 to $5 \mu \mathrm{m}$. Micro structural properties are also studied on the grinded surface with the help of digital electron microscope.
\end{abstract}

Keywords: Surface topography, Dynamometer, Wheel loading, Microscope.

\section{Introduction}

Titanium alloy (Ti-6A-4V) is known as the 'Work-Horse' of the titanium industry. Ti- $6 \mathrm{Al}-4 \mathrm{~V}$ is the most widely used titanium alloy. Pure titanium undergoes an allotropic transformation from the hexagonal close-packed alpha phase to the BCC beta phase at a temperature of $882.5^{\circ} \mathrm{C}\left(1620.5^{\circ} \mathrm{F}\right)$. For this reason, it has good mechanical and excellent machinability properties. For low to moderate temperature application, its performance is quite well. Beside this, low weight ratio, high strength, and corrosion resistance inherent to Ti-6Al-4V alloy has led to a wide range of successful applications. It is typically used for aerospace and racing car industry, Biomechanical applications, automotive industry Chemical industry Marine applications and Gas turbines. Biocompatibility of Ti- $6 \mathrm{Al}-4 \mathrm{~V}$ is also excellent. It is a $\alpha+\beta$ alloy which can be heat treatable to achieve increase in strength. Grinding of Ti-6A-4V is tough because it creates wheel loading, lump mass creating, and wheel sticking at the time of operation. But grinding is essential because it is one of those machining processes which offer a better mass production. it is techno economical too. When titanium is alloyed with small amounts of aluminium and vanadium, typically $6 \%$ and $4 \%$ respectively, by weight, this mixture has a solid solubility allowing it to undergo precipitation strengthening.

Paranjpe, Avadhoot ${ }^{[1]}$ did a study with Cooling Fluid- Water based emulsion (Up grinding, wheel speed $23 \mathrm{~m} / \mathrm{sec}$ ). They found in case of Ti-6Al-4V the ratio $F_{n} / F_{t} 1.5-1.8$ and no significant severe tool wear. Another study ${ }^{[2]}$ proved that solid lubricant also works fine 
with $\mathrm{SiC}$ grinding wheel and also found that Graphite reduces 30\% specific energy consumption almost\& considerably reduce friction. C. Ohkubo, I. Watanabe ${ }^{[3,4]} \mathrm{did}$ an experimental study on performance of Ti- $6 \mathrm{Al}-4 \mathrm{~V}$ alloy on surface grinding using chip formation and found that with the help of cryogenic cooling wheel adhesion reduces and Surface integrity improves distinctly. Long ribbon like chips is formed that indicates good surface finish. Turley ${ }^{[5]}$ did an investigation on the factors which affects surface finishing on grinding of titanium alloy (Ti-6Al-4V). Several similar types of research also carried out in order to select proper method of cooling during the grinding process ${ }^{[6,7]}$. In MQL grinding Synthetic oil gave better surface finish but vegetable oil gave better cooling effect.

In this context, this work investigates the surface morphology of Ti-6Al-4V alloy with digital microscope, after surface grinding with silicon carbide wheel under various cutting conditions.

\section{Experimental Facility}

The experiment is carried out on a surface grinder. The surface grinder is available in Manufacturing and production Engineering Laboratory, Dept. of Mechanical Engineering, Birbhum Institute of Engineering \& Technology. All the details of experimental techniques, models used are given below.

\section{A. Dynamometer Description}

The surface force measurement is carried out with the help of precision digital dynamometer. The details of dynamometer are described below:

\section{Digital I/O}

PCI/PXI-6527. 24 optically-isolated digital input channels and 24 solid-state relay output channels

Max input voltage 28 VDC

Isolation. 60 VDC (channel-to-channels)

Output capacitance $.55 \mathrm{pF}$ at $1 \mathrm{~V}$

Max switching voltage

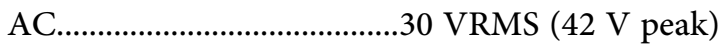

DC. $.60 \mathrm{VDC}$

Max switching capacity $120 \mathrm{~mA}$

Common-mode isolation $.60 \mathrm{VDC}$

Relay set time $(\max )$ $.3 .0 \mathrm{~ms}$

Relay reset time (max) $3.0 \mathrm{~ms}$

Power-on state ...Relays open

$5 \mathrm{~V}$ inputs $1.5 \mathrm{~mA} /$ channel max

$24 \mathrm{~V}$ inputs. $8 \mathrm{~mA} /$ channel max

\section{Physical}

Dimensions (not including connectors) 
PCI-6527. $17.5 \times 10.7 \mathrm{~cm}(6.9 \times 4.2$ in. $)$

PXI-6527 $16 \times 10 \mathrm{~cm}(6.3 \times 3.9 \mathrm{in}$.

I/O connector. 100-pin keyed female cable connector

\section{Power Requirement}

Power available at I/O connector. +4.5 to +5.25 VDC, fused

at $1 \mathrm{~A}$

To prevent the dynamometer from overheating, PXI chassis has been attached fans to handle which is 25 Watt per slot.

\section{B. Digital Microscope details}

I. DE5.0M Digital Eyepiece; CD-ROM of software and manual files; - Adaptor ring •USB2.0 Cable.

II. 32-bit color display at $1024 \times 768$ (64 MB video memory).

III. DirectX 9.0C or higher.

\section{Surface Grinder Specification}

All the experiments were conducted at surface grinder. The wheel speed is fixed at 2800 RPM on 50 cycle supply. The size of the grinding wheel is specified as $210^{\star} 20^{\star} 31.75$ $\mathrm{mm}$. Silicon carbide is used as the material of grinding wheel in order to reduce the wheel loading problem while grinding Ti alloys. The schematic diagram of the surface grinder is shown in Figure1.

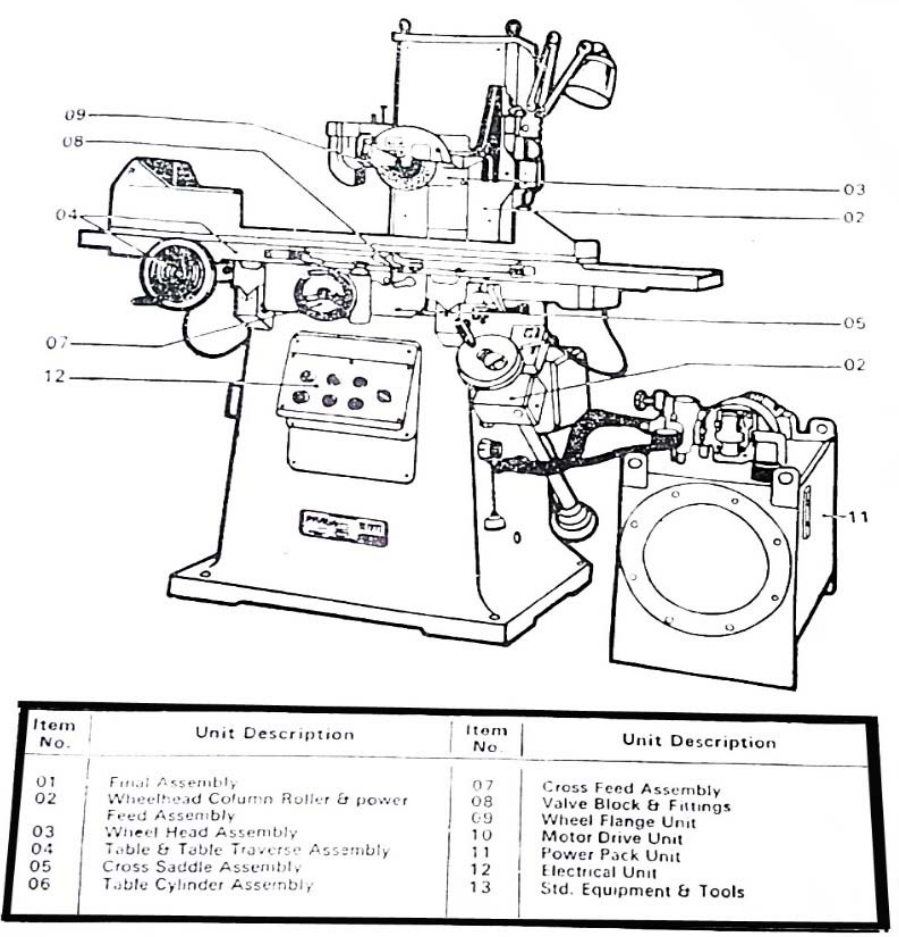

Figure 1: Schematic diagram of Surface Grinder 


\section{Experimental Procedure}

The study is mainly focused on the surface topographical features. However, different measured force component has also been presented here.

For this experiment $\mathrm{SiC}$ grinding wheel is used, but question is why it is been used for this particular experiment? The answer is $\mathrm{SiC}$ wheels are both harder and chemically very stable against non-ferrous alloys (the green type). Though we have two more options, Diamond and Cubic boron nitride but it is costly so cannot used in a techno economical process.

The grinding bed was fully magnetic but titanium has negative magnetic effect. So to neutralize the huge amount of force produced while grinding the solution was to fix the titanium bar in a fixture made of mild steel which has positive magnetic effect.

First of all, an AUTOCAD model of the fixture has been made and then manufactured it using various machining processes like removing extra material by abrasive cutter, grinding on HMT for better surface finish and drilling for holes which is used for alien bolts for gripping the titanium bar. Then inner threads are made by means of tapping. Fixture fitted with the work piece is shown below in Figure-2.

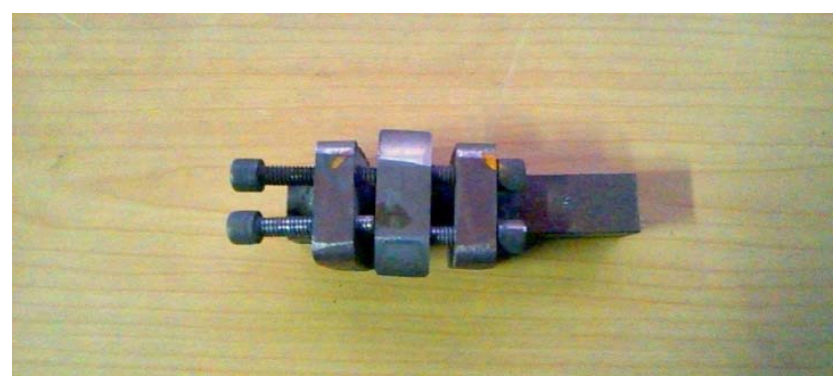

Figure 2: Work piece with fixture

Then this fixture fitted with workpiece is carefully placed in the bed of of the surface grinder and it is further engaged it magnetically. Then the digital dynamometer is connected with some suitable arrangement to the workpiece in the bed of surface grinder. This whole arrangement is shown in figure 3.

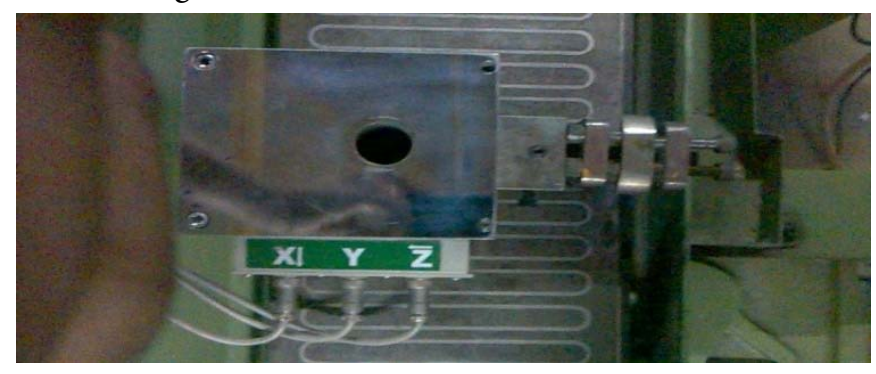

Figure 3: Fixture with Dynamometer fixed in Magnetic bed Process parameters of this process are as follows:

- Condition- Dry

- Process- Up Grinding

- Feed Variation- 0.04 to $0.4 \mathrm{~mm}$ 
- Radial depth of cut- 1 to $5 \mu \mathrm{m}$

- Dresser- Single point diamond dresser

- Depth of dressing- $0.01 \mathrm{~mm}$

- Dressing feed rate- $0.1(\mathrm{~mm} /$ revolution $)$

\section{Result \& Discussion}

\section{A. Force Measurement:}

Grinding is one of the effective machining processes. The ability to calculation of grinding force is important in many aspects of grinding. Proper process optimization, coolant system design, monitoring and control, is required. Compared to other machining processes, surface grinding requires large energy per unit volume. Let's for say, for the same amount of material removed, grinding takes much more energy and force compared to other machining process. The magnitude of the grinding forces and specific energy requirement are also very important indices of grindability. Work piece accuracy mostly depends on the force and amount of effective cooling arrangement. Temperature also plays an important role here. High grinding force implies machining tools wear faster. Compared to the other machining process, grinding requires much larger cutting forces (5-10 times) specific energy for same work material and same material removal rate. ${ }^{[9]}$ Grinding force can be further divided into normal component and tangential component $\left(\mathrm{F}_{\mathrm{N}}\right.$ and $\mathrm{F}_{\mathrm{H}}$ respectively). The grinding wheel is also subjected to the same forces as reactions but obviously in opposite direction. The grinding forces, $\mathrm{F}_{\mathrm{N}}$ and $\mathrm{F}_{\mathrm{H}}$ are very much analogous to the $\mathrm{P}_{\mathrm{Z}}$ and $\mathrm{P}_{\mathrm{XY}}$ of turning process. In conventional turning process ratio of $\mathrm{P}_{\mathrm{XY}}$ is half of $\mathrm{P}_{\mathrm{Z}}$. But in case of grinding process, $\mathrm{F}_{\mathrm{N}}$ is always much greater than (1.25-2 times) $\mathrm{F}_{\mathrm{H}}{ }^{[9]}$. The ratio of $\mathrm{F}_{\mathrm{N}}$ to $\mathrm{F}_{\mathrm{H}}$ here in this experiment is 2.1 for grinding depth of $2 \mu \mathrm{m}$, which is quite similar to the theoretical prediction. This is mainly due to the effect of penetration of grits into the work piece.

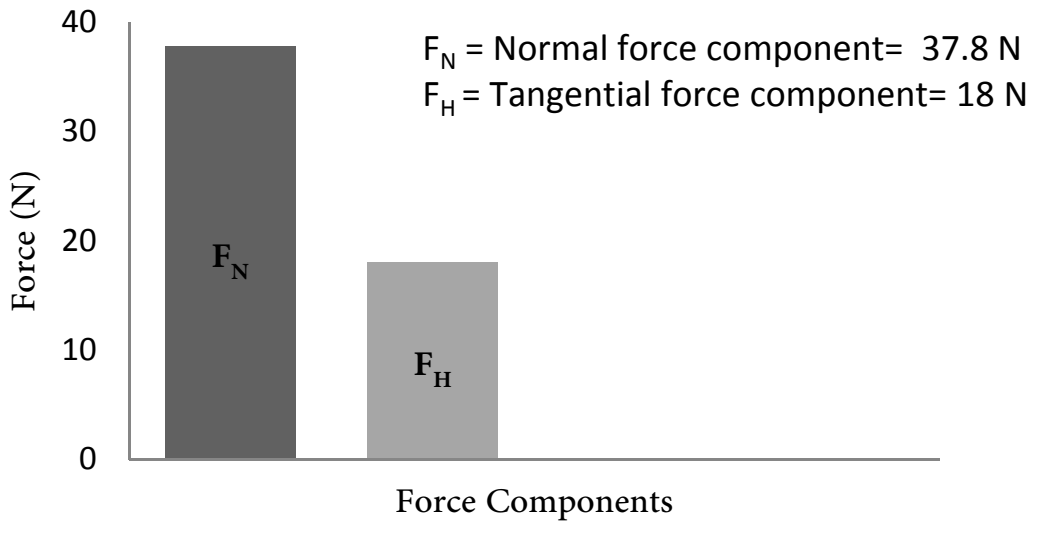

Figure 4: Comparison of Grinding force components 


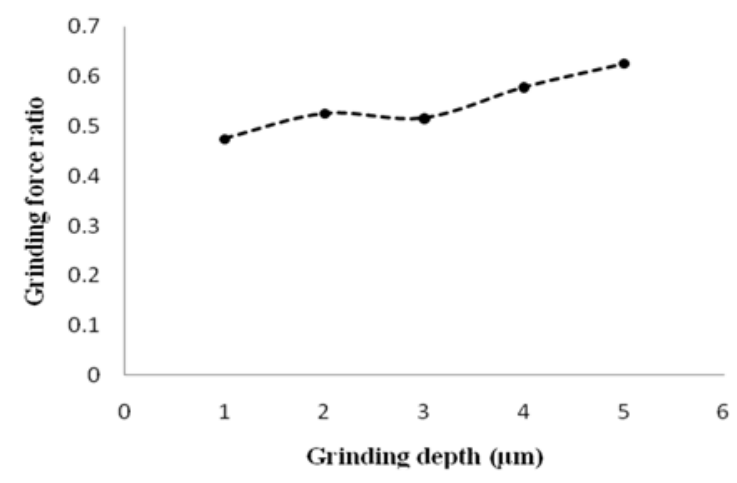

Figure 5: Grinding force ratio vs. Grinding depth

Grinding force ratio could be written as $\mathrm{F}_{\mathrm{H}} / \mathrm{F}_{\mathrm{N}}$ and expressed as [14],

$\mathrm{F}_{\mathrm{H}} / \mathrm{F}_{\mathrm{N}}=(2 / \Pi) \cot \beta+\mu$;

Where $\beta$ is the average value of cone apex semi-angle for grain cutting edge, and $\mu$ is the actual coefficient of friction. From Fig. 4 it can be concluded that, as depth of grinding increases, it leads to an increase in the penetration of grains in the zone of contact of the wheel and the work piece, which increases the grinding force ratio actually.

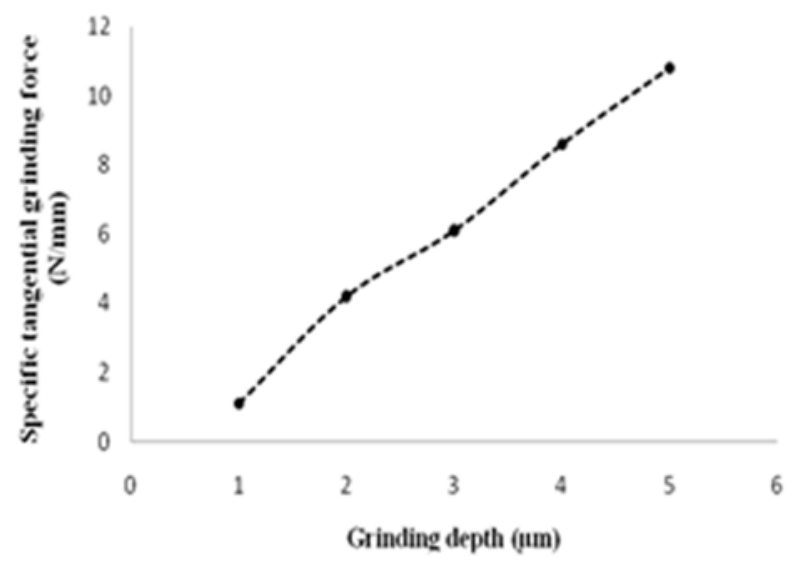

Figure 6: Specific tangential grinding force vs. grinding depth

Figure-6 shows the variation of specific tangential grinding force which is defined as the tangential force divided by the width of grinding with grinding depth in dry condition. From this figure it can be concluded that with the increase of grinding depth, tangential force increases almost linearly.

\section{Surface Morphology}

Surface morphology on the ground surface of a Ti-6Al-4V alloy in dry condition has been investigated with the help of digital microscope and these results are compared 
with different literature. Some common observations of this investigation are like surface damages due to rubbing of abrasive grits, plastic deformation, side material flow, and redeposition. Re-deposition is a process of adhesion and Welding of fine chip particles. Due to strong affinity of $\mathrm{Ti}$ alloys towards oxygen, nitrogen, carbon, it will undergo chemical reaction when they are in contact with each other. This chemical reaction would lead to a strong bonding of metal onto the top of the abrasive grits as this grits pass through the cutting zone. It will form an adhesion layer on grits and the layer increases gradually with time. In grinding, material removal is accomplished by different mechanism. These are discussed below in the context of this present experiment. Fig. $7 \mathrm{a}$ to $7 \mathrm{~d}$ represents digital microscope images of the machined surfaces after various cutting conditions.

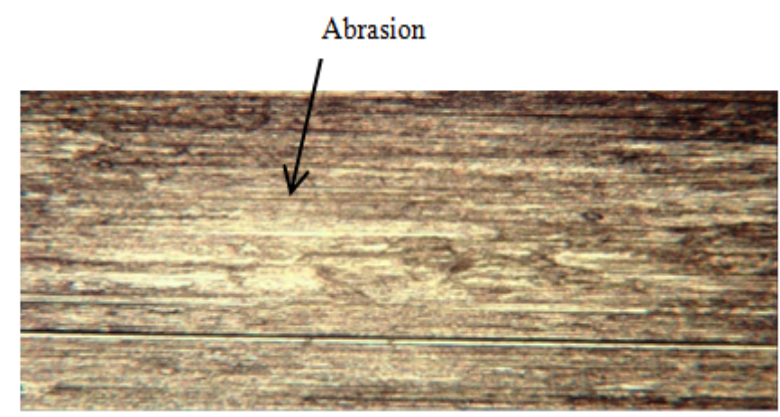

Figure 6a

Abrasion: It can be seen that machined surfaces present some scratches and grooves left by the abrasive grains which are irregular in nature.

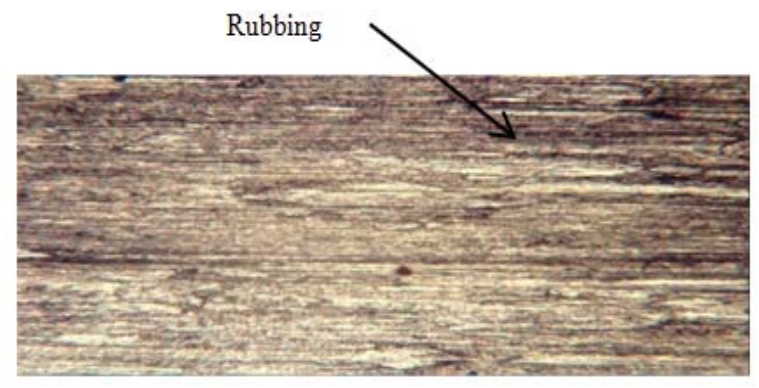

Figure 6b

Rubbing: Here two different modes of rubbing are spotted. In some spots where grit thickness reaching critical thickness due to rubbing by the tip of abrasive particles and some spots having rubbing of wear flats along the entire grit path. 


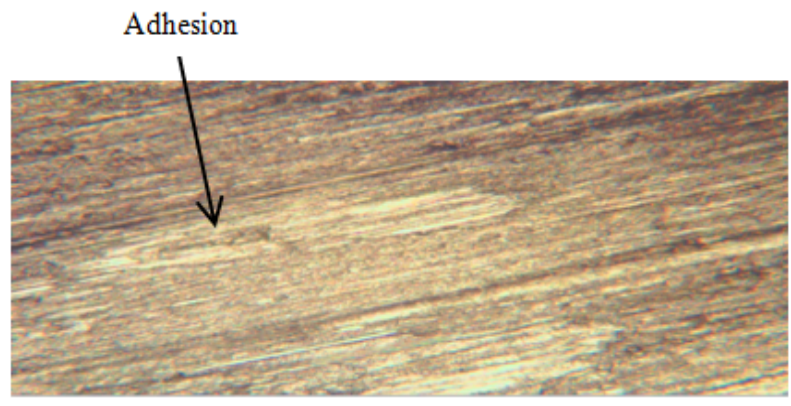

Figure 6c

Adhesion: Here some spots of rough and plastically deformed metal bands are observed which the result of high temperature oxidation is probably. Therefore metal from one surface are also trying to adhere to ground surface. When grinding a titanium alloy with a silicon-carbide wheel in dry condition, adhered metal layers will be formed with a thickness of $2 \mu \mathrm{m}$ or more as a result of adhesive process on the treated surface ${ }^{[10]}$.

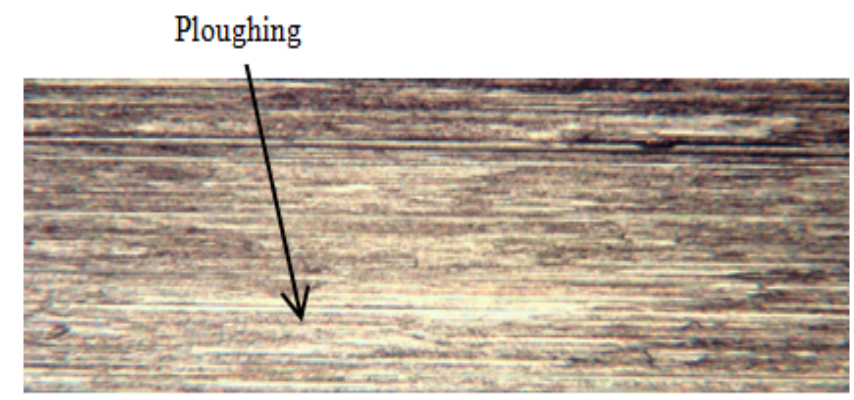

Figure 6d

Ploughing: Any ground surface would usually consist of grooves produced by ploughing ${ }^{[16]}$. Side wise displacement of work material is spotted due to high negative raked and pyramidal shape of abrasive grits. The chips that produced are leafy in appearances.

\section{Conclusion}

The following conclusions have been made based on the present investigation:-

- The surface was observed after grinding in dry condition with depth of cut $=5 \mu \mathrm{m}$, suggesting that this material was subjected to severe plastic deformation under this machining condition.

- From the morphology of the machined surfaces, it is evident that strong adhesion of chip to abrasive grain took place due to dry grinding. Some surface damages are observed in dry grinding which indicates grit wear of abrasives. The predominant of material removal mode is observed to be adhesion and plastic deformation. Also, in some cases re deposition of material is observed on the ground surface (Fig.4a and Fig.4c). 
- Micro cracks on the ground surface were not detected after machining in dry condition as depth of cut is low $(5 \mu \mathrm{m})$ where for higher depth of cut micro cracks are seen even with MQL technique. ${ }^{[1]}$ Turley [5] has investigated the factors that play influence on finishing during grinding of several grades of titanium alloys, stated that cracking occurs mostly on the re deposited material layers on the surface, and that they are formed when this layer is subsequently cooled. Redeposited material on the machined surfaces was also observed in the works carried out by $[12,13]$, who have evaluated the performance of conventional coolant and MQL techniques in grinding of titanium alloy in different cutting conditions. For this present experiment, although re deposition marks are spotted clearly but no micro cracks are observed.

- For dry grinding condition, specific tangential grinding force is small for low radial depth of cut ${ }^{[14]}$, so for low radial depth of cut, dry condition can be recommended. For this low depth of cut machining, it is even better compared to conventional flood cooling due to the effect of hydro dynamical of cutting fluid flow. ${ }^{[17]}$

\section{References:}

[1] Paranjpe, Avadhoot Residual stresses in machined titanium (Ti-6A1-4V) alloys 2127 Pages Publication Number1556206, 2014.

[2] E.O. Ezugwu, Z.M. Wang, Titanium alloys and their machinability- a review Journal of Materials Processing Technology Volume 23, 2012.

[3] C Ohkubo, I Watanabe, J.P Ford, H Nakajima, T Hosoi, T Okabe The Machinability of cast titanium and Ti6Al-4V Biomaterials, Volume 21, Issue 4, February2000, Pages 421-429.

[4] C. Ohkubo, I. Watanabe, J.P. Ford, H. Nakajima, T. Hosoi, T. Okabe Performance evaluation of Ti-6Al-4V grinding using chip formation and coefficient of friction under the influence of working fluids International Journal of Machine Tools and Manufacture,2015, 88, 237-248.

[5] D M. Turley Factors affecting surface finish when grinding titanium and a titanium alloy (Ti-6Al-4V)Wear, Volume 104, Issue 4,15 ${ }^{\text {th }}$ August 1985, Pages 323-335.

[6] Bijoy Mondal, Debashis Biswas, Anirban Sarkar, Santanu Das, Simul Banerjee. Grinding Performance using a Compound nozzle characterized by small discharge fluid Journal of The association of Engineers, India.

[7] S.Chandrasekar, M.C.Shaw, Cutting fluid performance in fine grinding Wear, Volume 86, Issue 1, 1 April 1983, Pages no 139-149.

[8] S.K.Bhaumik, C. Dvakar and A.K.Singh, Machining Ti-6Al-4V alloy with WBN-CBN composite tool, received 20January1995; accepted 7 December 1995.

[9] A.B. Chattopadhyay, Machining and Machine Tools, Wiley India

[10] S.V. Nosenkoa, V.A. Nosenkoa, L.L. Kremenetskiib, Condition of Machined Surface of Titanium Alloy in Dry Grinding, ICIE 2017, Procedia Engineering 206 (2017) 115-120, Science Direct. 
[11] AntonioVitor de Melloa, Rosemar Batista de Silvaa, Surface Grinding of Ti-6Al-4V Alloy with SiC Abrasive Wheel at Various Cutting Conditions, NAMRC 45, LA, USA, Procedia Manufacturing 10 ( 2017 ) 590 - 600, Science Direct.

[12] Sadeghi, M. H., Hadad, M. J., Tawakoli, T., Emami, M. 2009. Minimal quantity lubrication-MQL in grinding of Ti-6Al-4V. The International Journal of Advanced Manufacturing Technology, vol. 44, p. 487-500.

[13] Setti, D., Sinha, M. K., Ghosh, S., Rao, P.V. 2015. Performance evaluation of Ti-6Al-4V grinding using chip formation and coefficient of friction under the influence of nanofluids. International Journal of Machine Tools \& Manufacture, vol. 88, p. 237-248.

[14] Guoqiang Guo, Zhiqiang Liu b, Investigation on surface grinding of Ti-6Al-4V using minimum quantity lubrication, Advanced Materials Research Online: 2012-04-12 ISSN: 1662-8985, Vol. 500, pp 308-313.

[15] R.A. Irani, R.J. Bauer, A. Warkentin: Int J Mach Tools Manuf. Vol. 45(2005), p. 1696-1705.

[16] Monith Biswojyothi, A.S.S.Balan, N.Arunachalam, L.Vijayaraghavan, A study on the minimum quantity lubrication in grinding of titanium alloy (Ti-6Al-4V), (AITMDR 2014) December 12th-14th, 2014, IIT Guwahati, Assam, India.

[17] M.H. Sadeghi, M.J. Hadad, T. Tawakoli, A. vesali and M. Emami: Int Journal of Material Form Vol. 3(2010), p. 241-251.

\section{Authors' Profile:}

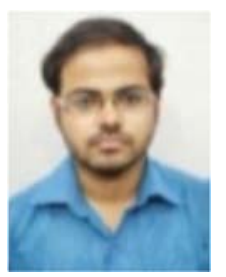

Mr. Aritras Roy obtained his M.E (2015-17) from Jadavpur University in the Department of Power Engineering. Now working in a DRDO COPT project as a project officer and currently working as a research scholar (Dept of Applied Mechanics) at IIT Madras (2017 onwards). His research areas include Experimental aerodynamics and CFD, wind power.

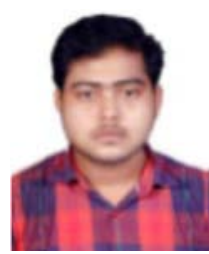

Sudin Kumar Kundu received his B.Tech degree from Birbhum Institute of Engineering \& Technology under Maulana Abul Kalam Azad University of technology on 2015. Previously he has worked on manufacturing of techno-economic multipurpose lubrication system for Surface Grinder \& Engine Lathe during his graduation. This work is advanced and revised part of author's final year graduation project in collaboration with co-authors.

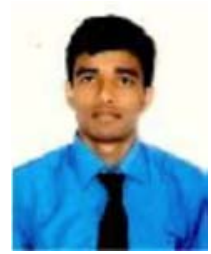

Kanchan Maji received his B.Tech degree from Birbhum Institute of Enfineering \& Technology under Maulana Abul Kalam Azad University of Technology on 2015. Previously he has worked on manufacturing of techno-economic multipurpose lubrication system for Surface Grinder \& Engine Lathe during his graduation. This work is advanced and revised part of author's final year graduation project in collaboration with co-authors. 